\title{
EVOLUÇÃO DA POLÍTICA DE CRÉDITO RURAL NO BRASIL: UMA ANÁLISE HISTÓRICA
}

\author{
Larissa Naves de Deus Dornelas ${ }^{1}$
}

\begin{abstract}
RESUMO
Este artigo tem como objetivo analisar a evolução da política de crédito rural no Brasil desde a criação do Sistema Nacional de Crédito Rural (SNCR), em 1965, até a atualidade. Parte-se da ideia de que a política de crédito subsidiado aos agricultores constitui importante e forte instrumento de apoio ao setor, sobretudo num contexto em que se observa o avanço das relações capitalistas também no campo. Neste sentido, o artigo remonta à criação do SNCR, em que se identifica uma clara estratégia de desenvolvimento agropecuário por parte do governo, seu desenvolvimento e crise, além de ressaltar o estado atual da política de crédito rural brasileira. Para tanto, utilizará da revisão bibliográfica como metodologia, percorrendo a bibliografia condizente com o tema numa perspectiva histórica.
\end{abstract}

Palavras-chave: Desenvolvimento rural, política de crédito rural, Sistema Nacional de Crédito Rural.

\section{EVOLUTION OF RURAL CREDIT POLICY IN BRAZIL: A HISTORICAL REVIEW}

\section{ABSTRACT}

This article aims to analyze the evolution of rural credit policy in Brazil from the creation of the National Rural Credit System (SNCR), in 1965, to the present. It starts from the idea that the credit policy subsidized to important constituents and a strong instrument to support the sector, especially in a context in which the advance of capitalist relations is also observed in the field. In this sense, the article goes back to the creation of the SNCR, which identifies a clear agricultural development by the government, its development and crisis, in addition to highlighting the current state of Brazilian rural credit policy. For that, it will use the bibliographic review as a methodology, going through the bibliography consistent with the theme in a historical perspective.

Keywords: National System of Rural Credit. rural credit policy. rural development. JEL: Q14; Q18; O18.

\footnotetext{
${ }^{7}$ Graduada em Ciências Econômicas (UFU). Mestrado em Economia (UFU). Doutorado em Economia (UFU). Professora Colaboradora do Departamento de Economia da Universidade Estadual do Centro-Oeste do Paraná (UNICENTRO). E-mail: larissand6@hotmail.com
} 


\section{INTRODUÇÃO}

A política de crédito subsidiado ao setor agrícola tem ganhado cada vez mais importância no debate econômico. A análise da relevância do crédito rural na história econômica brasileira torna imprescindível o entendimento de como se deu a consolidação do atual padrão tecnológico existente na agricultura do País. Isto, pois, as características do atual padrão tecnológico hegemônico na agricultura brasileira remontam à chamada Revolução Verde, que caracterizou-se pelo esforço de internacionalizar o processo de apropriacionismo, já característico no desenvolvimento da agricultura dos países desenvolvidos. Ou seja, este movimento significou "o esforço de modernização da agricultura do Terceiro Mundo" (GOODMAN et al., 1990, p. 34), em que atividades, antes puramente rurais, passaram a ser subordinadas ao capital, de modo a facilitar o processo de acumulação no bojo do sistema capitalista.

Pode-se caracterizar esse novo padrão tecnológico do meio rural a partir de quatro esferas. Na esfera da produção observa-se a utilização crescente dos processos mecânicos e de insumos químicos. Destaca-se, ainda, a importância distintiva das inovações biológicas, que atuam no sentido de se reduzir a dependência da terra e do clima, tornando as relações no campo menos dependentes da natureza e mais atreladas aos processos industriais. Na esfera da circulação das mercadorias redefinem-se as relações com o capital comercial tradicional, com aumento de seu peso e importância, sobretudo, devido ao aumento das capacidades e possibilidades de armazenamento da produção neste novo contexto. Na esfera do funcionamento da atividade agropecuária observa-se a consolidação do crédito rural subsidiado em lugar do capital usurário tradicional, o que viabiliza e facilita o processo de modernização no campo. Por fim, na esfera das relações de emprego pode-se verificar a expansão do trabalho assalariado, enquanto há a submissão das formas tradicionais de parceria e outras formas de trabalho remuneradas em espécie.

Para além, observa-se fortemente a intensificação das relações contratuais no campo nesta etapa do atual processo tecnológico hegemônico da agricultura. Deste modo, o que se observa é que "a dinâmica da agricultura passava a ser compreendida pela dinâmica conjunta da indústria para a agricultura e da agricultura para a agroindústria: constituem e se consolidam os Complexos Agroindustriais (CAls)" (SOUZA; CAUME, 2008, p. 8).

A consolidação do atual padrão tecnológico hegemônico da agricultura brasileira, com as referidas características, só foi possível mediante o desenvolvimento do Sistema Nacional de Crédito Rural (SNCR), na década de 1960, período considerado um divisor de águas do desenvolvimento agrícola brasileiro. Até meados dos anos 1960 haviam fortes transferências da renda do setor agrário para o projeto de industrialização da economia brasileira, com destaque à importância da exportação nesse período, além de se ter a política cambial como principal instrumento de política econômica. Já no período pós-1965, observam-se mudanças da base técnica/produtiva da produção rural, com forte modernização e industrialização do campo.

Destaca-se neste contexto a importância do credito rural como política orientada à consolidação do novo padrão tecnológico da agricultura no Brasil, sobretudo via criação do SNCR. Basicamente o crédito rural busca cumprir os seguintes objetivos: estimular o incremento ordenado dos investimentos rurais; favorecer o custeio oportuno e adequado da produção e a comercialização dos produtos agropecuários; possibilitar o fortalecimento econômico dos produtores; incentivar a introdução de métodos racionais de produção, visando o aumento da produtividade e a melhoria do padrão de vida das populações rurais (BANCO DO 
BRASIL, 2004). Neste sentido, os novos aparatos monetários e financeiros criados favoreceram este novo cenário agrícola no Brasil, uma vez que "a modernização da agricultura requer a existência de um sistema financeiro constituído (...) para que possa ser viabilizada e, ao mesmo tempo, esse sistema passa a ser fundamental na soldagem dos CAls com o movimento global da acumulação" (GRAZIANO, 1996, p. 26).

Tendo em vista a relevância e papel distintivo do crédito rural no contexto da modernização da agricultura brasileira este artigo tem como objetivo analisar a evolução da política de crédito rural no Brasil a partir da constituição do SNCR até meados da década de 2000. Especificamente, analisar-se-á a origem do SNCR, seu desenvolvimento e crise, assim como o atual estágio da política de crédito rural no país. Para cumprir este objetivo, a revisão bibliográfica de materiais dedicados a entender esta temática será utilizada como metodologia. Serão referenciados tanto textos que abordam o contexto e cenário econômico em que fora desenvolvido o SNCR, assim como a literatura especializada em política de crédito rural.

Para tanto o artigo está estruturado em três seções, além desta introdução e das considerações finais. Na primeira seção será apresentado o cenário em que fora constituído e implementado o SNCR, além de suas principais características e modo de funcionamento. Na segunda seção será analisado o desenvolvimento da política de crédito rural realizada por meio do SNCR, assim como o desmantelamento da mesma. Em seguida, na terceira seção busca-se apresentar os principais aspectos e características da atual política de crédito rural no Brasil.

\section{ORIGEM E CARACTERÍSTICAS DO SNCR}

Entendida como um mecanismo de concessão de crédito às atividades agropecuárias, com taxas de juros e condições de pagamento favoráveis ao produtor do campo, a política de crédito rural constitui um dos principais instrumentos da política agrícola brasileira no sentido de apoio ao setor. A criação do SNCR, em 1965 pelo governo federal, consolidou oficialmente este apoio ao setor agropecuário no Brasil (RAMOS; MARTHA JUNIOR, 2010).

A análise da origem do SNCR, assim como seu modo de funcionamento requer o entendimento acerca do contexto em que fora criado. Delgado (1985) considera haver duas fases bem definidas que dizem respeito ao papel do setor agrícola no processo de desenvolvimento econômico do período pós-guerra, sendo a década de 1960 considerada o divisor de águas desses períodos. Num primeiro momento, enquanto a política econômica tinha seus esforços voltados à industrialização do país, o setor agrícola era visto como fonte de transferência de recursos para esse projeto industrializante, sobretudo via renda gerada pela exportação cafeeira, além das condições externas terem contribuído sobremaneira para tal objetivo. Já a partir da segunda metade da década de 1960, observa-se a modificação dessa estratégia de transferência de recursos. Novos objetivos de política econômica passaram a ser delineados, sendo eles relacionados à estabilidade de preços, salários e equilíbrio cambial, de modo que surgem novas demandas relacionadas à maior integração das relações intersetoriais (interindustrial e internacional do setor agrícola).

Essas demandas por maior integração das relações intersetoriais remetem à própria mudança do papel da agricultura no processo de desenvolvimento econômico. Deixa-se de lado a visão restrita da agricultura apenas como um setor, e passa-se a ganhar relevância uma visão do campo como espaço, ou seja, uma análise mais ampla acerca das relações existentes no campo, fato que coincide com a emergência dos chamados Complexos Agroindustriais (CAls). 
De um modo geral, pode-se dizer que, após montado o setor de bens de capital e insumos básicos (constituição do chamado D1) na economia brasileira, o sistema econômico passa a adquirir novos contornos, mais complexos e integrados com a economia mundial. Somado a isso, a internacionalização do capital e a difusão da Revolução Verde viabilizam a modernização/industrialização da agricultura (D1 da agricultura), "fazendo emergir a nova categoria do Complexo Agroindustrial Rural" (DELGADO, 1985, p. 63).

Neste novo contexto, a dinâmica da agricultura passa a ser guiada pelo padrão de acumulação industrial, tendo a ação do Estado papel primordial no sentido de orientar a modernização da agricultura ${ }^{2}$. Além disso, o papel do Estado se estende ao poder criar condições necessárias à expansão e reprodução do setor, ou seja, "o novo centro dinâmico da economia - a indústria e a vida urbana - impõe suas demandas ao setor agrícola e passa a condicionar suas transformações, que vão conduzindo ao domínio dos complexos agroindustriais" (GRAZIANO, 1996, p. 5).

A estrutura destes novos CAls refletem uma dinâmica que extrapola os mecanismos internos da própria atividade agrícola. Observa-se, ainda, neste tocante, que a dicotomia 'mercado interno x mercado externo' perde importância, uma vez que, neste novo contexto, é a dinâmica conjunta entre agricultura e indústria a relevante. Em outras palavras:

\begin{abstract}
Essa interpretação põe em evidência duas ideias fundamentais: a de que a produção agrícola passou a constituir um elo de uma cadeia, negando por completo as antigas condições do complexo rural fechado em si mesmo e em grande parte as do complexo agro-comercial prevalecente até os anos 60; e que o processo de constituição do CAI - e da industrialização da agricultura, que é um momento mais avançado da modernização - só se pôde efetivar a partir da implantação da 'indústria para a agricultura', isto é, do departamento fornecedor de máquinas e insumos para a agricultura (GRAZIANO, 1996, p. 24, grifos do autor).
\end{abstract}

A lógica de funcionamento dos CAls, ao integrarem e interagirem diversas atividades distintas, se traduz no fato de que todas as atividades são atividades a serviço do capital. As ligações existentes entre as atividades, como uma simples compra de insumos para a atividade agrícola, deixam de ser apenas técnicas e passam a contemplar também, e sobretudo, o aspecto financeiro. Neste sentido, a necessidade técnica implica, de maneira conjunta, a necessidade financeira, tendo o sistema financeiro papel diferencial uma vez que "se torna um parâmetro a soldar o movimento da agricultura com o movimento geral da economia" (GRAZIANO, 1996, p. 26).

Tendo em vista tal aspecto é que se entende a importância do desenvolvimento de um sistema financeiro moderno e abrangente no contexto do processo de modernização da agricultura. Sendo a produção rural cada vez mais integrada, e, suas atividades, atividades do capital, é preciso haver financiamento dessas atividades. Neste ponto, destaca-se a perspectiva desenvolvida por Keynes, em 1937, acerca da importância do motivo finance para demandar moeda.

O motivo finance designa "a demanda por moeda antecipada a alguma despesa discricionária planejada” (CARVALHO et al., 2007, p. 53). Como expresso

\footnotetext{
${ }^{2}$ Neste trabalho considera-se a modernização da agricultura nos termos de Graziano (1996), no sentido de indicar o processo de transformação na base técnica da produção agropecuária no pós-guerra a partir da passagem da agricultura 'natural' para uma que utiliza insumos fabricados industrialmente.
} 
por Keynes (1937) ao analisar o circuito finance-investimento-poupança-funding, o investimento se dá em duas etapas. Primeiramente há a demanda por recursos pelos empresários no período entre a decisão de investir e a realização do investimento (finance) e, posteriormente, o investimento em si. Deste modo, o finance funciona como um fundo rotativo, fornecido pelas instituições financeiras, utilizado para estimular a atividade econômica. A inexistência do finance, ou mesmo a dificuldade para acessar tais recursos, dificultam a boa dinâmica da atividade econômica, e, estendendo ao tema do presente trabalho, causam problemas no financiamento das atividades oriundas dos CAls. Logo, o que se observa é a necessidade de um sistema financeiro integrado no processo de desenvolvimento capitalista na agricultura, sendo que, além disso, é preciso que as políticas no âmbito financeiro sejam auxiliares neste contexto.

Para além da questão do financiamento das atividades agroindustriais, a necessidade de crédito rural se justifica também pelas peculiaridades envolvidas na produção das atividades rurais. Essas peculiaridades referem-se tanto aos riscos inerentes a qualquer investimento, como risco de capital, mas também aos riscos associados a fatores climáticos e sanitários, capazes de inviabilizar a produção agrícola, ou mesmo riscos referentes ao comportamento dos preços. Destaca-se neste ponto que, diferentemente do que ocorre na indústria, na agricultura há um distanciamento do tempo de produção e do tempo de trabalho durante o processo produtivo. O que se está em pauta é que, em estruturas capitalistas, o valor da mercadoria pode ser compreendido através do trabalho morto -consumo constante do capital incorporado na mercadoria - e o trabalho vivo, que é "o tempo de trabalho socialmente necessário à reprodução da força de trabalho" (MANN; DICKSON, 1987, p.15).

Deste modo, observa-se que o processo de acumulação de capital na agricultura adquire contornos que se distanciam do processo produtivo contínuo, havendo forte dependência dos fatores naturais, aumento dos tempos de nãotrabalho, além do dispêndio maior de tempo de produção em relação aos setores industriais. Neste sentido, tem-se como consequência uma rotação do capital mais lenta, o que cria obstáculos ao desenvolvimento capitalista no campo, fato que contribui para o aumento dos riscos inerentes às atividades rurais.

Delgado (1985) aponta que, a partir de 1965, três inovações foram introduzidas no sistema de incentivos da política econômica e da política monetária brasileira, constituindo peças chaves de incentivo à agropecuária. Em primeiro lugar, instituiu-se um sistema de subsídios creditícios à modernização da agropecuária e uma forma particular de financiamento desse sistema, com a institucionalização e operação do SNCR. Em segundo lugar, adotaram-se medidas de subsídio às exportações, sob a forma de isenções, créditos fiscais e taxas de juros favorecidas ao setor exportador. E, por fim, abandonou-se o regime de taxas de câmbio fixo, e, em seu lugar, adotou-se o sistema de minidesvalorizações, o que contribuiu para a diversificação da pauta exportadora brasileira, que passou a contar produtos oriundos dos CAls, agroindustrializados.

Criado a partir da Lei 4.829/65, o SNCR tinha sua regulamentação atribuída ao Conselho Monetário Nacional e o controle de suas ações ao Banco Central. Seus objetivos principais estavam pautados no estímulo ao incremento ordenado dos investimentos rurais, inclusive para armazenamento, beneficiamento $e$ industrialização dos produtos agropecuários, quando efetuado por cooperativas ou pelo produtor rural em sua propriedade; no favorecimento ao custeio oportuno e adequado da produção e comercialização dos produtos agropecuários; no fortalecimento econômico dos produtores rurais, notadamente pequenos e médios; e, no incentivo à introdução de métodos racionais de produção, visando ao aumento de 
produtividade e melhoria do padrão de vida das populações rurais e à adequada defesa do solo.

O financiamento rural era previsto pela referida Lei em três modalidades: custeio, sendo o crédito destinado a cobrir despesas normais de um ou mais períodos da produção agrícola ou pecuária; investimento, sendo o crédito destinado a inversões em bens e serviços cujos desfrutes fossem realizados no curso de vários períodos; e, comercialização, sendo o crédito destinado, isoladamente, ou como extensão do custeio, a cobrir despesas próprias da fase sucessiva à coleta da produção, sua estocagem, transporte ou à monetização de títulos oriundos da venda pelos produtores. Em outras palavras, essa institucionalidade defina que:

\begin{abstract}
[...] cabia ao crédito de investimento agir como mecanismo do estímulo ao processo de adoção de novas tecnologias agrícolas, ao de custeio permitir a compra de insumos modernos e ao de comercialização carregar o estoque de produto no tempo, evitando a concentração da oferta na época da safra (RAMOS; MARTHA JÚNIOR, 2010, p. 18).
\end{abstract}

No tocante às fontes de financiamento destaca-se a incorporação no sistema de financiamento à agricultura, antes baseado, sobretudo, no Banco do Brasil, dos bancos regionais, do Banco Nacional de Crédito Cooperativo, dos bancos estaduais, dos bancos privados, das sociedades de crédito, financiamento e investimentos e das cooperativas.

As fontes de financiamento se dividem, como ressaltado por Delgado (1985), em expansão passiva do crédito, que é geralmente aceita como não-inflacionária, e em expansão ativa do crédito. A diferença principal reside no fato de que enquanto na primeira o financiamento é provido através de recursos previamente disponíveis (saldos de depósitos à vista dos bancos comerciais; recursos fiscais e para-fiscais dos Fundos e Programas Agrícolas administrados pelo Banco Central; outros recursos das Autoridades Monetárias), no segundo caso, o banco cria débitos contra si em favor de um tomador, ou seja, expande o crédito sem base previa de depósitos. Neste sentido, em 1967, após Resolução do Conselho Monetário Nacional, foi regulamentada a obrigatoriedade dos bancos aplicarem $10 \%$ de seus depósitos à vista na concessão de crédito ao setor agropecuário, constituindo assim, na origem do SNCR, a expansão passiva do crédito a principal fonte de financiamento da política de crédito rural.

Deste modo, pôde-se observar nesta seção o contexto específico em que o SNCR fora instituído, além da apresentação de seus principais objetivos e modo de funcionamento enquanto ponto central da política de crédito rural brasileira. Analisase, em seguida, como se deu o funcionamento do SNCR nos moldes de sua criação, em termos de resultados e de sua efetividade, assim como o período de crise em que passou o sistema.

\title{
3. DA CONSTITUIÇÃO AO DESMANTELAMENTO DO SNCR
}

O SNCR operou, desde sua constituição, em 1965, com taxas de juros reais negativos, sendo a captação de seus recursos dependente de provisão e regulamentação das autoridades monetárias. Inicialmente, ao se considerar o período de 1969 a 1979, observou-se forte aumento dos recursos destinados à política de crédito rural, com altas taxas implícitas de subsídios, que contribuíram fortemente para "uma mudança na base técnica da produção rural" (DELGADO, 1985, p. 80).

Tendo em vista a fonte de financiamento do SNCR no período acima citado, pode-se considerar que a expansão do crédito rural provinha de expansão passiva, 
oriunda das exigibilidades existentes que previam a aplicação compulsória dos depósitos à vista dos bancos comerciais em financiamento à agricultura; dos recursos fiscais, para-fiscais e de origem externa; e, dos saldos de depósitos à vista do Banco do Brasil. Essa expansão passiva de recursos permitia o comportamento crescente dos subsídios a taxas cada vez menores (até mesmo negativas, uma vez que eram menores que a taxa de inflação, que girou em média de $40 \%$ na década de 1970). Dessa forma:

Segundo Bacha (1997), durante a década de 1970, a maior parte dos recursos do crédito era de fontes sem custos. Isso permitia a concessão de empréstimos à taxa de juros nominal inferior à taxa de inflação, implicando em taxa de juros real negativa. Uma taxa de juros real negativa significa um subsídio ao produtor rural, sendo que ocorre uma transferência de renda do agente que concede o crédito àquele que toma (RAMOS; MARTHA JÚNIOR, 2010, p. 18).

Além das taxas de juros durante o período serem negativas, vale destacar, no bojo do funcionamento do SNCR, a participação majoritária do Banco do Brasil como emprestador rural, contemplando uma participação mínima de $53 \%$ do total, enquanto nos últimos anos alcançou a marca de 75\% dos empréstimos (MATA, 1982 , p. 223). Sua participação peculiar se deve, dentre outros motivos, ao desinteresse de parte dos bancos privados nesse tipo de operação, que além de envolver os riscos inerentes à produção agrícola, estava desenhada num cenário de taxas de juros muito baixas, reduzindo consideravelmente a margem de rentabilidade. Dessa forma, "como reflexo da estrita observação dessas regras gerais de financiamento do sistema financeiro privado tem-se, como resultado, a sua não-participação, a não ser compulsoriamente nos financiamentos à atividade agrícola" (FÜRSTENAU, 1987, p. 146).

Por outro lado, ao se considerar os anos 1980 em diante, observa-se que as condições macroeconômicas da economia brasileira contribuíram para um movimento de desarticulação desse projeto modernizante da agricultura. Neste período observouse, além das crises internacionais do petróleo e do aumento dos juros internacionais, o aumento significativo da inflação e de problemas fiscais no Brasil. Com isso, "retraise inicialmente o crédito por investimento (1980), acompanhado da redução no crédito para comercialização, também em 1980. Finalmente, inibe-se e retrai-se o crédito para custeio da safra (capital de trabalho) em 1981, recuperando-se ligeiramente em 1982" (DELGADO, 1985, p. 80).

Neste ponto, destaca-se a mudança na estrutura de financiamento do crédito rural. Como já mencionado, enquanto nos anos 1960 e 1970 a expansão do crédito rural se dava, sobretudo, pela via passiva, passou a se dar pela via ativa. Essa mudança de orientação decorreu da queda rápida do ritmo de crescimento da economia, o que reduziu a base de recursos que alimentava os fundos destinados ao crédito agrícola, assim como diminuiu os depósitos à vista, tendo em vista a aceleração inflacionária. Deste modo:

A solução encontrada para atender essa questão não deixou de ter impacto sobre a oferta de moeda, por intermédio da criação ativa de moeda bancária pelo Banco do Brasil. Esse comportamento bancário prescinde do respaldo prévio de aumento dos depósitos do público e de elevação das reservas bancárias, repousando, em última instância, nas emissões primárias das autoridades monetárias (DELGADO, 1985, p. 73). 
O instrumento criado pelo Banco do Brasil para contornar essa situação foi a conhecida 'Conta Movimento', que, resumidamente, tinha como objetivo evitar o descompasso entre a disponibilidade de recursos e a necessidade de financiamento de programas do interesse do governo. Deste modo, havia a possibilidade de liberação de recursos por meio de financiamentos sem a correspondente previsão no orçamento. Com isso, "o suprimento de recursos ao Banco do Brasil, que era pra ser realizado pelos depósitos à vista, passou a ser feito quase que exclusivamente pela Conta Movimento (...) [que] assumiu proporções gigantescas e tornou-se uma poderosa fonte de expansão da oferta monetária" (RAMOS; MARTHA JÚNIOR, 2010, p. 20).

Entretanto, diante do contexto de ajuste fiscal requerido pelo governo, além da crescente tendência inflacionária, que já vinha desde a década de 1970, a Conta Movimento foi extinta em 1986, sobretudo por funcionar como instrumento facilitador da expansão monetária, o que causava pressões na inflação.

O novo cenário macroeconômico trouxe um conjunto de políticas de cunho mais ortodoxo por parte do governo. Como consequência, houve um realinhamento da orientação da política de crédito rural, com a redução da participação direta do governo na concessão dos financiamentos e a retirada progressiva dos subsídios ao crédito. Mais especificamente:

(...) as principais alterações efetuadas durante a década foram: (a) redução da participação das autoridades monetárias como fonte de recursos; (b) uso mais intensivo de recursos próprios dos produtores; (c) reforma nas contas públicas e unificação orçamentária; (d) extinção da conta movimento do Banco do Brasil em 1986 e instituição da poupança rural e (e) criação da Secretaria do Tesouro Nacional, que passou a controlar as operações realizadas por ordem do Tesouro Nacional (RAMOS; MARTHA JÚNIOR, 2010, p. 22).

Com essas medidas o que se observou foi um processo de restrição do crédito à agricultura nos anos 1980 e 1990. Por um lado, houve a limitação da parcela da produção a ser financiada, restringindo inicialmente o acesso ao crédito pelos grandes e médios produtores, o que, posteriormente, atingiu a todas as faixas de produtores. Por outro lado, observou-se a elevação das taxas de juros para os empréstimos rurais, equiparando-as às taxas vigentes no mercado, altas, diga-se de passagem (FÜRSTENAU, 1987).

Deste modo, fica claro o desmantelamento do SNCR aos moldes em que fora criado. A conjuntura econômica, enquanto favorável, auxiliou a expansão creditícia ao setor, beneficiando não apenas os produtores rurais, mas, como analisado na seção anterior, todo o complexo agroindustrial em desenvolvimento. Entretanto, com a crise fiscal do governo, somada à aceleração inflacionária e às condições internacionais, a orientação da política rural foi revertida, impactando a expansão do crédito rural. Assim, de acordo com Kageyama (1990), a política agrícola, diante deste cenário, passou a enfatizar a política de garantia de preços mínimos (PGPM) no lugar do crédito rural subsidiado, como tentativa de um instrumento capaz de assegurar os preços recebidos pelos produtores rurais e garantir a rentabilidade do setor. Logo:

No início dos anos 80, a PGPM teve um caráter mais ativo no processo de financiamento do setor agrícola, cujos objetivos deveriam ser a garantia da rentabilidade dos produtores rurais e o fornecimento de crédito para a comercialização dos produtos 
transacionados dentro dos Complexos Agroindustriais, além de limitar a atuação do Governo no financiamento do setor, pois agora os escassos recursos deveriam ser administrados caso a caso (MASSUQUETTI, 1998, p. 202).

A partir do que fora analisado, pode-se constatar o papel distintivo do Estado enquanto provedor da modernização da agricultura brasileira, sobretudo via operacionalização do SNCR, com taxas de juros negativas, papel forte do principal banco público na concessão dos empréstimos, além da expansão de subsídios ao setor. Entretanto, a eficiência dessa política de crédito rural, sobretudo em termos da abrangência dos beneficiários, é questionável. Conforme apontam Souza e Caume (2008), o SNCR foi um instrumento extremamente seletivo na orientação do crédito rural, uma vez que induziu o processo de modernização da agricultura de maneira desigual em termos de produtores, produtos e regiões. Mais especificamente:

O crédito rural e os subsídios a ele vinculados privilegiaram, sobretudo, os grandes proprietários de terras e as empresas rurais, em detrimento dos pequenos produtores, que permaneceram à margem das vantagens (em 1976, os grandes produtores foram responsáveis por $3 \%$ dos contratos firmados e $53 \%$ dos recursos captados no Sistema, enquanto os pequenos produtores foram responsáveis por $73 \%$ dos contratos firmados e absorveram apenas $11 \%$ dos recursos ofertados). As culturas destinadas à exportação ou substitutivas de importações, como o café, a cana, a soja, o algodão e o trigo, receberam um volume de crédito superior à sua participação no valor da produção nacional; em oposição às culturas ligadas ao mercado e às necessidades internas (feijão, mandioca e milho), cujas margens de participação no crédito foi muito inferior à sua importância na produção. Do mesmo modo, o SNCR, ao favorecer os produtores das regiões mais desenvolvidas (Centro-Sul), em detrimento das mais atrasadas (Norte e Nordeste), intensificou as desigualdades regionais (SOUZA; CAUME, 2008, p. 9).

No mesmo sentido, Mata (1982) argumenta que o SNCR acabava por favorecer os produtores que estavam mais próximos dos mercados consumidores e das agências bancárias, fazendo com que houvesse a auto seleção dos agricultores que conseguissem se adequar às características do Sistema. Além disso, há questionamentos acerca dos casos de desvio de recursos, de substituição de capital e do gasto excessivo do Governo com esta política, sobretudo ao utilizar taxas de juros negativas num contexto de aceleração inflacionária.

Entende-se, assim, que o SNCR auxiliou e propiciou a modernização da agricultura brasileira, num período de peculiar importância, que coincide com emergência dos CAls, apesar das inúmeras críticas quanto a abrangência do Sistema. Entretanto, o modo como o Sistema fora concebido requeria uma conjuntura econômica favorável para que a expansão do crédito subsidiado fosse garantida.

Como ressaltado, com a reversão do ciclo econômico, passando a economia brasileira a apresentar problemas fiscais e aceleração da inflação, fortes cortes foram realizados na composição do SNCR, e, a intervenção do Estado de maneira direta em termos de política de crédito rural, como até então era realizada, foi deixando de ser contemplada. Deste modo, analisa-se na próxima seção como a política de crédito rural reverteu o desmantelamento do SNCR, além de apresentar as características principais da política de crédito rural na atualidade. 


\title{
4. POLÍTICA DE CRÉDITO RURAL: DOS ANOS 1990 À ATUALIDADE
}

A orientação da política econômica, de modo geral, está condicionada à conjuntura macroeconômica de uma economia. Isso pode ser observado pelo funcionamento da política de crédito rural, através do SNCR, desde os anos 1960 à década de 1980. Nos anos 1990 não foi diferente. Neste período a economia brasileira ainda tentava se livrar da alta inflação, que foi conseguido através do Plano Real em 1994/95. Ademais, o país se atrelava aos ideais do chamado Neoliberalismo, em que se pregava, dentre outros aspectos, a necessidade de maior abertura econômica e financeira e redução do papel do Estado na economia.

Como resultado, o papel do Estado passou a ser o de agente regulador e estimulador, e, no tocante à política de crédito rural, o foco se voltou à busca de fontes alternativas de recursos e na atuação dos agentes privados no financiamento da agricultura, muito diferente de seu papel nas décadas de 1960 a 1980. De forma a retratar tal mudança de orientação, observou-se:

\begin{abstract}
Dessa forma, a orientação do Governo Fernando Henrique Cardoso era tornar a atividade agrícola competitiva no mercado internacional, em termos de qualidade e preço dos produtos. Para isso, os produtores rurais 'devem tornar-se empresários rurais eficientes, com informações e visão abrangente da cadeia produtiva e dos negócios, inseridos num mercado competitivo (BRUM, 1997, p. 543). Além disso, buscava-se garantir a oferta de produtos agrícolas a preços compatíveis, utilizando o recurso de importação desses produtos, se fosse preciso, e 'continuar a subsidiar a produção, mas de forma moderada e talvez em um grau declinante para não aumentar o déficit público, lançar mão de importações sempre que a produção nacional não for suficiente para atender ao consumo ou para segurar os preços' (BRUM, 1997, p. 543) (MASSUQUETTI, 1998, p. 118).
\end{abstract}

Entretanto, essa orientação de política criou inúmeras dificuldades aos agricultores, sobretudo aos pequenos, que não conseguiam níveis de produtividade suficiente para o novo cenário de competitividade internacional. Basicamente o setor agrícola sofria a ausência de uma efetiva política agrícola, que, segundo Massuquetti (1998), buscou apenas retirar o setor agrícola de uma crise, mas não protegê-lo. Dessa forma, "as consequências da falta de percepção sobre a crise no setor ocasionaram a falência de diversos produtores, o aumento do desemprego no setor rural e a redução da área plantada e da produção na safra 1995/96" (MASSUQUETTI, 1998, p. 121).

Como exemplo das medidas criadas para tentar superar a crise que o setor agrícola sofria frente à redução dos recursos de financiamento e à abertura comercial, pode-se elencar o aumento da carteira de aplicações agropecuárias do BNDES; a criação de programas de investimento - Programa de Incentivo ao Uso de Corretivos de Solo e o Programa de Incentivo à Mecanização, o Resfriamento e ao Transporte Generalizado da Produção de Leite ${ }^{3}$; e as alternativas de financiamento, que de públicas passaram a ser privadas, majoritariamente (RAMOS; MARTHA JÚNIOR, 2010).

\footnotetext{
${ }^{3}$ Neste ponto destaca-se que a abertura comercial e a formação do Mercosul penalizaram sobremaneira o produtor brasileiro de leite e exigiu esforços específicos de modernização da atividade para que pudesse alcançar melhore níveis de competitividade, o que justifica tal Programa instituído em 1999 (RAMOS; MARTHA JúNIOR, 2010).
} 
Em relação às alternativas de financiamento, em 1994 foi instituída a chamada Cédula de Produto Rural, um título emitido por produtores rurais e cooperativas, que tinha a finalidade de captar recursos para capital de giro, funcionando como um capital antecipado para custeio da produção. Com relação ao crédito de investimento observa-se a substituição dos recursos tradicionais do crédito rural, aos moldes da instituição do SNCR, pelos recursos 'com destino certo', como no caso dos repasses realizados pelo BNDES através de linhas específicas de crédito para determinados setores e agroindústrias. Para além, destaca-se uma nova modalidade de financiamento privado, resultado de uma combinação entre crédito de investimento e comercialização, denominado Contrato de Investimento Coletivo (SOUZA; CAUME, 2008).

O fato de maior destaque, entretanto, da década de 1990 reside no aumento considerável da dívida dos produtores rurais, em virtude, sobretudo, do descasamento entre a correção dos preços mínimos e a correção dos financiamentos contraídos nas instituições financeiras. "A partir do plano Collor I a correção dos preços mínimos pelo IPC foi de $41,28 \%$ enquanto a dívida, corrigida pelo mesmo indicador, foi corrigida em 84,23\%" (GIMENES et al., 2008, p. 5). Para Ramos e Martha Júnior (2010), os antecedentes dessa crise de endividamento dos produtores rurais guardam relação com as medidas adotadas na década de 1980, em que objetivava-se reduzir a oferta de crédito e os subsídios ao financiamento via indexação das taxas de juros. Ademais, some-se a isso o patamar alto das taxas de juros atreladas a um câmbio extremamente valorizado no bojo do Plano Real, o que prejudicou os produtores em termos de preços baixos e custos muito elevados.

Assim, tendo em vista tal contexto, cria-se um amplo programa de renegociação das dívidas dos produtores rurais, denominado Programa de Securitização, instituído em 1996. Na primeira fase do programa previa-se o auxílio no pagamento de dívidas de até $R \$ 200.000,00$, com prazo de pagamento de sete anos e juros de 3\% a.a. acrescidos da variação dos preços mínimos. Essa fase contribui para restaurar a liquidez do setor agrícola e restabelecer a capacidade dos produtores em conseguir novos financiamentos, embora, na prática, as dificuldades para a contração de novos empréstimos prevalecia, sobretudo em virtude da rigidez das instituições financeiras a cederem novos empréstimos e do comprometimento das garantias dos produtores estarem atreladas à renegociação da dívida (RAMOS; MARTHA JÚNIOR, 2010).

A segunda fase do programa permitia que produtores rurais com dívidas superiores a $\mathrm{R} \$ 200.000,00$ fossem enquadrados no Programa Especial de Saneamento de Ativos, em que o produtor adquiria títulos do governo no valor correspondente a $10,37 \%$ do valor da dívida junto às instituições financeiras, com prazo de resgate de vinte anos. Conforme explicita Grossi et al.(2008) apud Ramos e Martha Júnior (2010), essa fase beneficiou os grandes devedores, já que, segundo dados do Banco do Brasil, aproximadamente $74 \%$ do valor dos contratos renegociados neste programa correspondiam a dívidas superiores a $R \$ 1$ milhão, de responsabilidade de apenas $9 \%$ dos beneficiários, o que contribui para evidenciar, uma vez mais, a abrangência parcial da política de crédito rural.

Já a terceira fase do Programa de Securitização acrescentou as dívidas enquadráveis no Programa de Revitalização de Cooperativas de Produção Agropecuária, tendo como objetivo reestruturar e capitalizar as cooperativas de produção agropecuária visando seu desenvolvimento autossustentado, com prazo de pagamento de 15 anos e taxa de juros de 9,75\% a.a. Desde modo, contempladas as três fases do Programa, tem-se que ele foi uma medida necessária no momento em questão, pois, as tentativas de estabilização da economia provocaram distorções nas 
taxas de juros dos financiamentos dos produtores rurais, levando à alta taxa de inadimplência (GIMENES et al., 2008).

Conforme apontam Ramos e Martha Júnior (2010), na segunda metade da década de 1990 a agenda do governo sofreu modificações, sobretudo em virtude da estabilização da moeda conseguida pelo Plano Real, da intensificação do movimento de abertura comercial e introdução das questões relacionadas à inclusão social e econômica. No tocante à política de crédito rural a concessão dos empréstimos seguiu critérios rígidos por parte dos agentes financeiros, houve maior pulverização do crédito subsidiado, maior participação de formas alternativas de financiamento, além da atuação do governo ser mais seletiva, tendo como foco a agricultura familiar - digase de passagem, até agora não vista de perto por parte da política de crédito rural - e o financiamento por meio do BNDES.

Destacam-se neste contexto a criação de dois programas em específico. O primeiro, Programa de Geração de Emprego e Renda Rural, foi instituído em 1995 e tinha como objetivo o desenvolvimento de atividades rurais e o fomento à geração de trabalho, emprego e renda dos micro e pequenos negócios rurais. E, em 1996 há a criação do Programa Nacional do Fortalecimento da Agricultura Familiar, que continha o claro objetivo de reparar o viés seletivo da política de crédito rural até então em pauta. A instituição desse Programa,

(...) resulta, ainda, do reconhecimento por parte de setores governamentais de que o fortalecimento da agricultura familiar é estratégico para a criação de novas atividades econômicas geradoras de ocupações produtivas e de renda; e, da constatação de que nada adiantaria o esforço do governo para assentar trabalhadores sem-terra, que viriam aumentar o contingente de produtores familiares se uma massa enorme dos já existentes encontrava-se na iminência de perder suas terras e, até mesmo, a sua própria condição de vida (SOUZA; CAUME, 2008, p. 19).

Torna-se claro, que há uma mudança na orientação da política de crédito rural ao longo dos anos 1990, no sentido favorável. Após meados de 1995, com a moeda estabilizada e a economia relativamente equilibrada passa-se a aumentar o montante de recursos destinados à agricultura, tendo como base o final dos anos 1980 e início dos anos 1990. Ademais, destaca-se os programas direcionados criados em 1995 e 1996, que passavam a olhar de perto pelos pequenos produtores e, sobretudo, pelos agricultores familiares, além do objetivo de se desenvolver atividades rurais capazes de absorver mão-de-obra no campo.

Essa tendência de aumento do crédito rural iniciada após 1995 se estende com mais intensidade nos anos 2000. Como exemplo, cita-se os anos de 1997 e 1999 em que volume de crédito rural cresceu $3,6 \%$, atingindo a marca de $R \$ 28,9$ bilhões, enquanto que, entre 2000 e 2005 cresceu $70,8 \%$, chegando a $R \$ 50,8$ bilhões. Já na segunda metade dos anos 2000 o crescimento observado foi de $148 \%$, totalizando R $\$ 75$ bilhões em 2009 (RAMOS; MARTHA JÚNIOR, 2010).

Pode-se atribuir esse crescimento à equalização das taxas de juros no período, o que propiciou o aumento dos recursos por parte do governo, a renegociação das dívidas dos produtores, iniciada com o Programa de Securitização, a criação da Cédula do Produtor Rural em 2001, mas, sobretudo, às diversas linhas de financiamento e novos programas criados. A título de exemplificação, citem-se $O$ Programa de Apoio à Agricultura Irrigada; o Programa de Plantio Comercial de Florestas; Programa de Incentivo à Construção e Modernização de Unidades 
Armazenadoras em Propriedades Rurais, dentre outros, que, posteriormente, ficaram conhecidos como 'família de programas BNDES' (RAMOS; MARTHA JÚNIOR, 2010).

Dessa forma, observa-se uma tendência de crescimento do crédito rural no Brasil a partir dos anos 1995, tendência essa que se intensifica nos anos 2000 e se confirma na atualidade, com crescimento observado de 41\% de 2013 a 2014, totalizando $R \$ 120$ bilhões aproximadamente. Com isso, fica clara a indicação da importância e relevância do crédito rural não só enquanto facilitador do processo de desenvolvimento e modernização do rural no Brasil, mas, e, sobretudo, ao próprio desenvolvimento da agricultura em meio à dinâmica capitalista. Destaca-se ainda, a importância fundamental da orientação da política de crédito rural recente ao focalizar os pequenos produtores e os agricultores familiares, que antes, principalmente dos anos 1960 a 1980 não foram contemplados com os subsídios ao setor.

\section{CONSIDERAÇÕES FINAIS}

Este trabalho procurou analisar, numa perspectiva história, a evolução da política de crédito rural brasileira, desde a criação do SNCR até meados da década de 2000. Parte-se da ideia de que o crédito tem importância distintiva para apoiar a dinâmica de uma economia, fato esse que se adequa para a análise das relações existentes no campo, em que o crédito rural é indispensável instrumento de apoio ao crescimento e sustentação das atividades rurais.

Neste ponto, destaca-se a importância da institucionalização do SNCR no contexto específico em que se observava no Brasil o processo de desenvolvimento das relações capitalistas no campo. Nesse processo, houve a emergência dos chamados CAls, em que as relações do campo deixam de ser estritamente rurais e passam a estar a serviço do capital, havendo uma interdependência entre as relações do campo e as industriais. É justamente ao se analisar este contexto que o SNCR se torna tão relevante, já que o financiamento a essas atividades passa a ser fundamental. Como apontado por Graziano, a necessidade técnica (imposta pela modernização do campo) implica, de maneira conjunta, a necessidade financeira, tendo o sistema financeiro papel diferencial uma vez que "se torna um parâmetro a soldar o movimento da agricultura com o movimento geral da economia" (1996, p. 26). Assim, entre a década de 1960 e 1970, o SNCR funcionou de maneira a subsidiar o crédito aos produtores rurais, funcionando, inclusive, com taxas de juros negativas. Neste período houve modernização da agricultura, desenvolvimento e fortalecimento das atividades agroindustriais.

Já os anos 1980 significaram o desmantelamento do SNCR aos moldes como fora criado. Em virtude do cenário externo desfavorável, somado à crise fiscal brasileira aliada à aceleração inflacionária, houve forte redução dos recursos destinados ao SNCR. Somente após a estabilização monetária, conseguida pelo Plano Real, em 1994/95, que a política de crédito rural voltou a se reestabelecer e contar com mais recursos. Porém, ao contrário da fase inicial, nos anos 1990 e 2000 as fontes de recursos passaram a ser cada vez mais privada, tendo o Estado retirado seu papel direto de apoio ao setor.

Destaca-se, na atualidade o crescimento extraordinário dos recursos destinados à política de crédito rural, tenho o ano de 2014 terminado com o valor aproximado de $\mathrm{R} \$ 120$ bilhões. Para além, vale destacar o avanço da política de crédito rural nos últimos anos ao atuar de maneira mais direta voltada aos pequenos produtores rurais e aos agricultores familiares. Como analisado ao longo do trabalho, o funcionamento do SNCR recebeu inúmeras críticas relacionadas à sua seletividade, beneficiando, majoritariamente, os médios e grandes produtores, que tinham acesso facilitado ao crédito. Neste sentido, a política de crédito rural, sobretudo após 1996 
com a criação do PRONAF, avança ao buscar apoiar de maneira mais eficiente os produtores que mais necessitam do crédito para dinamizarem sua produção e mesmo para manterem a agricultura de subsistência.

Por fim, vale ressaltar o quanto um instrumento de política econômica do governo depende da conjuntura econômica em questão para lograr êxito em seus objetivos, como observado pela política de crédito rural. Entretanto, não basta uma conjuntura econômica favorável, é indispensável haver a vontade política e a consciência da necessidade de apoio a determinadas atividades, e determinados agentes de uma economia. Logo, o que se pretende frisar é que cada vez mais as decisões relevantes do futuro de uma economia estão nas mãos dos policy makers, que devem estar atentos à dinâmica econômica e ao futuro que esperam traçar para determinada sociedade.

\section{REFERÊNCIAS}

BANCO DO BRASIL. Evolução histórica do crédito rural. Revista de Política Agrícola, Ano XIII, n. 4, p.10-17, out./dez. 2004.

BRASIL. Lei no 4.829, de 5 de novembro de 1965. Institucionaliza o crédito rural. Congresso Nacional, DF, 5 nov. 1965.

CARVALHO, F. C. et al. Economia monetária e financeira: teoria e política. Rio de Janeiro: Campus, 2007.

DELGADO, G. Capital financeiro e agricultura no Brasil. ICONE/UNICAMP, São Paulo. 1985.

FÜRSTENAU, V. A política de crédito rural na economia brasileira pós 1960. Ensaios FEE, Porto Alegre, v. 8, n.1, p139-154, 1987.

GIMENES, R. M. T., GIMENES, F. P., GOZER, I. C. Evolução do crédito rural no Brasil e o papel das cooperativas agropecuárias no financiamento dos produtores rurais. In: XLVI CONGRESSO DA SOCIEDADE BRASILEIRA DE ECONOMIA, ADMINISTRAÇÃO E SOCIOLOGIA RURAL, XLVI., 2008. Rio Branco. Anais... Rio Branco, 2008.

GOODMAN, D.; SORJ, B.; WILKINSON, J. Das lavouras às biotecnologias. Editora Campus Ltda. 1990.

GRAZIANO DA SILVA, J. A nova dinâmica da agricultura brasileira. Campinas, Editora da UNICAMP, 1996.

KAGEYAMA, A. O novo padrão agrícola brasileiro: do complexo rural aos complexos agroindustriais. In: DELGADO, G. et al. (org). Agricultura e políticas públicas. Brasília: IPEA, 1990.

KEYNES, J. M. Alternatives theories of the interest rate. Economic Journal, v. 47, n.186, p. 241-252, 1937.

MANN, S.; DICKINSON, J. M. Obstáculos ao desenvolvimento da agricultura capitalista. Literatura Econômica, Rio de Janeiro, IPEA, n. 1, v. 9, p. 7-26, fev. 1987. 
MASSUQUETTI, A. A mudança no padrão de financiamento da agricultura brasileira no período 1965-97. 1998. 223 f. Dissertação (Mestrado em Economia Rural) - Centro de Estudos e Pesquisas Econômicas da Faculdade de Ciências Econômicas da Universidade Federal do Rio Grande do Sul (UFRGS), Porto Alegre, 1998.

MATA, M. Crédito rural: caracterização do sistema e estimativa dos subsídios implícitos. Revista Brasileira de Economia, Rio de Janeiro, v. 36, p. 3, p. 215-245, jul./set. 1982.

RAMOS, S. Y., MARTHA JÚNIOR, G. B. Evolução da política de crédito rural brasileira. Planaltina, DF: Embrapa Cerrados, 2010.

SOUZA, C. B., CAUME, D. J. Crédito rural e agricultura familiar no Brasil. In: XLVI CONGRESSO DA SOCIEDADE BRASILEIRA DE ECONOMIA, ADMINISTRAÇÃO E SOCIOLOGIA RURAL, XLVI., 2008. Rio Branco. Anais... Rio Branco, 2008. 